\title{
Inhibition of canine duodenal interdigestive myoelectric complex by nutrient perfusion of jejunal and ileal Thiry-Vella loops
}

\author{
J C SCHANG, F A NGE, A LAMBERT, F C RENNER, \\ M APR A H A I A N, A ND J F GRENIER \\ From the Pavillon Chirurgical B, Hospices Civils, Strasbourg, France
}

SUMMARY The mechanisms by which the intestinal interdigestive myoelectric complex (IDMEC), recurring at about 90 minute intervals in the fasted dog, is disrupted by feeding remain unknown. We investigated whether the IDMEC could be disrupted in the duodenum by perfusing a ThiryVella loop with glucose in the dog. An intestinal Thiry-Vella loop, measuring one half (80 to $160 \mathrm{~cm}$ ) of the total length of the small bowel was constructed in four dogs from the jejunum, and in four other dogs from the ileum. Extracellular nichrome electrodes were sewn on the duodenum for recording the electrical activity of the intestine. After three weeks' recovery, electrical recordings were performed in the fasted dogs in order to observe whether the IDMEC persisted in the duodenum when the Thiry-Vella loops were perfused, at different days, for four hours with solutions made of either (1) $\mathrm{NaCl} 154 \mathrm{mM}$, (2) $\mathrm{NaCl} 308 \mathrm{mM}$, (3) glucose $300 \mathrm{mM}$, or (4) glucose $600 \mathrm{mM}$, at a rate of $8 \mathrm{ml} / \mathrm{min}$. $\mathrm{NaCl} 308 \mathrm{mM}$ and glucose $600 \mathrm{mM}$ were also delivered at a rate of $4 \mathrm{ml} / \mathrm{min}$. Glucose output from the Thiry-Vella loops was measured throughout the experiments over consecutive five minute intervals. Each experiment was performed three times in each dog. The results showed that perfusing the Thiry-Vella loops with $\mathrm{NaCl} 154 \mathrm{mM}$ or $\mathrm{NaCl} 308 \mathrm{mM}$ did not suppress the IDMEC in the duodenum whether the flow rate was 4 or $8 \mathrm{ml} / \mathrm{min}$. On the contrary, perfusing the jejunal loops with glucose $300 \mathrm{mM}$ disrupted the IDMEC in $54 \%$ of the experiments: perfusing glucose $600 \mathrm{mM}$ disrupted the IDMEC in $83 \%$ of the experiments. In the ileal Thiry-Vella loop experiments, the IDMEC was disrupted in $33 \%$ of the cases with glucose $300 \mathrm{mM}$ and in $66 \%$ of the cases with $600 \mathrm{mM}$. No significant difference was observed with glucose $300 \mathrm{mM}$ delivered at a rate of $8 \mathrm{ml} / \mathrm{min}$ and glucose $600 \mathrm{mM}$ delivered at a rate of $4 \mathrm{ml} / \mathrm{min}$. Finally, the inhibitory effect of perfusing the Thiry-Vella loops with glucose increased as the amount of absorbed glucose increased. These results indicate that interruption of the IDMEC by feeding probably involves extraintestinal factors. These factors do not seem to be specific for any one part of the small intestine, but they seem to be activated by intestinal absorption.

The interdigestive myoelectric complex (II)MEC) has been well documented over the last few years. This cyclic pattern of the electric spiking activity of the small bowel wals first described by Szurszewski ${ }^{1}$ in dogs. The myoelectric complex occurs only in the fasting state and consists of four sequential phasses recycling regularly at about 90 minute intervals. Phase $I$ is characterised by the

Received for publication 17 March 1981 absence of spike potentials. Phase II consists of irregular spiking activity. Phase III is a short period. lasting about five minutes, during which the maximal rate of spiking activity is reached. Finally, phase IV is a transition between regular spiking activity and quiescence.

Feeding interrupts the IDMEC for several hours and induces a pattern of irregular, intermittent spiking activity. This postfeeding activity demonstrates considerable change from one nutrient to another.": The reappealrance of phase 111 marks 
the end of the period of IDMEC interruption and regularly recurring cycles continue thereafter.

The mechanisms which control the postfeeding disruption of the IDMEC are incompletely understood. Previous work has shown that necessary requirement for interruption of the IDMEC by nutrient meals was the contact of the intestinal mucosa with these meals, ${ }^{4}$ intravenous feeding being without effect on the IDMEC:" However, little information is available about the pathways through which mucosal contact with the nutrients leads to the interruption of the IDMEC. The purpose of our work was to determine whether perfusion of canine jejunal or ileal Thiry-Vella dogs with different nutrient solutions would alter the IDMEC in the duodenum.

\section{Methods}

EX P ER I M ENTA I. PREPARATION

This study was carried out on eight dogs weighing 14 to $16 \mathrm{~kg}$. They were anaesthetised with sodium thiopental $(30 \mathrm{mg} / \mathrm{kg}$ ) and a caeliotomy was performed. The small intestine was measured from the ligament of Treitz to the ileocaecal junction. Then, the howel was transected midwaly between the ligament of Treitz and the ileocaecal junction. In four dogs, the jejunum was also divided $10 \mathrm{~cm}$ distal to the ligament of Treitz and the intervening segment of jejunum was fashioned into a Thiry-Vella (TV) loop (fig 1). In the other four dogs. the terminal ileum was divided $10 \mathrm{~cm}$ proximal to the ileocaecal junction and the intervening segment of ileum was fashioned into a ThiryVella loop. In all dogs, the intestinal coniinuity was re-established by end-to-end anastomosis. I:our pairs of Nichrome wire electrodes were sewn to the serosat of the duodenum at $5 \mathrm{~cm}$ intervals. The other ends of the wires were tunnelled subcutane-

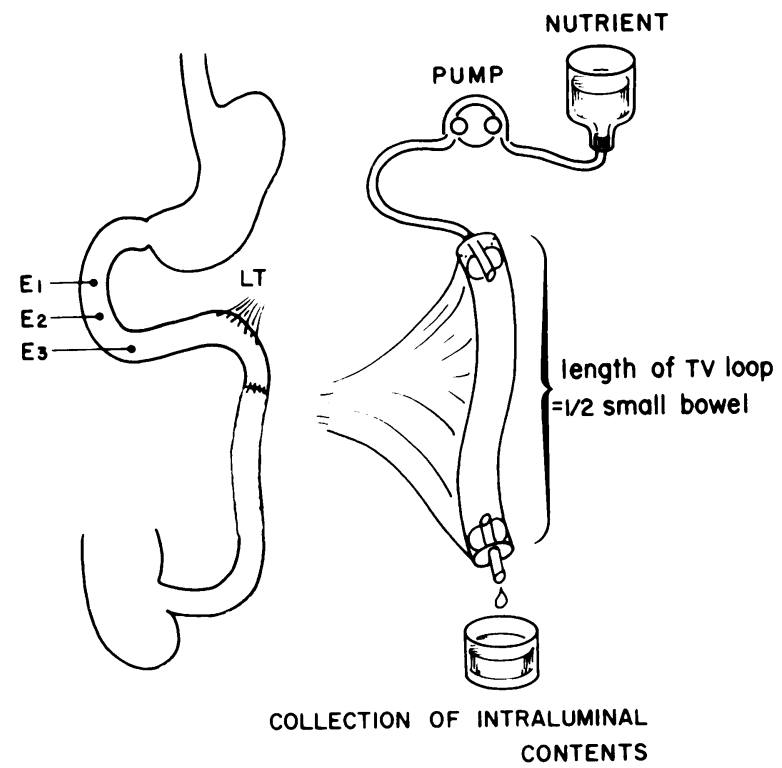

Fig. 1 Experimental preparation; E1, E2, E.3 are electrodes on the duodenum; LT is the ligament of Treitz.

ously and brought out in the interscapular region. No electrode was placed on the Thiry-Vella loop. The dogs were allowed three weeks' recovery before experiments were started.

\section{E I. F C T R I C A I R E C O R I) I N ( i S}

The electrical recordings were obtained by connecting the electrodes to an eight-channel Beckman R 411 Dynograph recorder. Such a tracing is shown in Fig. 2, which represents the three phases of the myoelectric complex. The signals were amplified through $\mathrm{R}-\mathrm{C}^{\prime}$ coupled amplifiers with a time constant of $(0 \cdot() 1$ second. The electrical

PHASE II PHASE III PHASE I

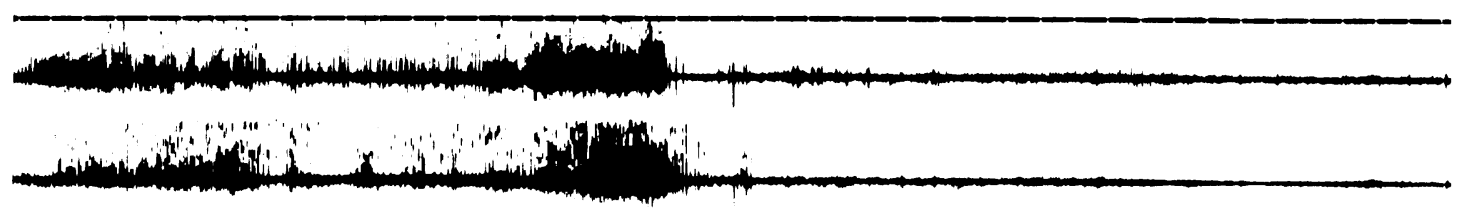

15 minutes

Fig. 2 Electrical tracing recorded from two electrodes, 3 cm apart on the duodenum of a fasted dog. Phases I. II, and III of the myolectric complex are easy to recognise. Phase IV is not mentioned because it does not appear clearly on this particular tracing. 
signals recorded from each electrode were also processed through an on-line analysis system working on real time. This system" allowed us to count automatically the number of slow waves. as well as the number of slow waves superimposed with spike potentials. Each slow wave bearing spikes wals indicated by a marker on the graphic record.

PER F U S A T ES

Control recordings were performed in the absence of perfusion. Other recordings were made while perfusing the Thiry-Vella loops. at different days. with one of the following solutions: (1) $\mathrm{NaCl}$ $154 \mathrm{mM}$; (2) $\mathrm{NaC} 308 \mathrm{mM}$; (3) glucose 300$) \mathrm{mM}$; and $(4)$ glucose $600 \mathrm{mM}$. The solutions were perfused continuously at a rate of $8 \mathrm{ml} / \mathrm{min}$, which is in the range of the flow rate in the canine jejunum after feeding a standard meal. $-\mathrm{NaCl} 308 \mathrm{mM}$ and glucose 600$) \mathrm{mM}$ were also infused at a constant rate of $4 \mathrm{ml} / \mathrm{min}$. The length of the period of infusion was four hours (Fig. 3).

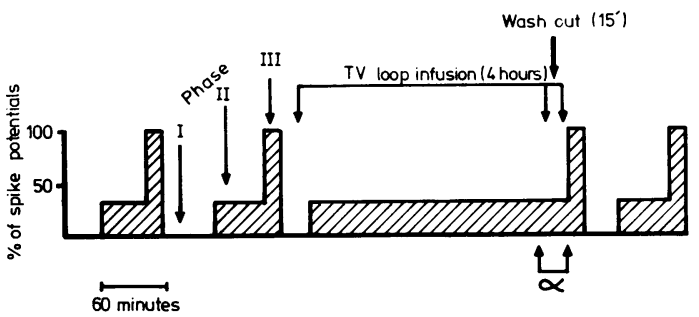

Fig. 3 Conduct of the experiment: at least one cycte of the IIDMEC (with phases I, II, and III) was recorded before the perfusion of the Thiry-Vella loop was done for four hours. a indicates the time elapsing between the end of the perfusion and the reoccurrence of phase $I I I$ of the $I D M E C$.

Perfusions were performed by inserting a polyethylene tube with an occluding balloon in the proximal stoma of the Thiry-Vella loop. The perfusion rate was controlled with a pump (Gilson Minipuls 2). The effluent from the other end of the Thiry-Vella loop was collected at five minute intervals.

At the end of the perfusion period the ThiryVella loop was washed out by irrigating with a solution of $\mathrm{NaCl} 154 \mathrm{mM}$ at a rate of $8 \mathrm{ml} / \mathrm{min}$ for 15 minutes. This irrigation allowed us to quantify the amount of glucose remaining in the loop at the end of the perfusion period.

(ONDLCT OH 1:XPLRIMENT (Fig. 3)

Lach experiment wals performed on fully conscious dogs fasted for 24 hours. The dogs were allowed to move within a cage which measured $2 \times 2 \times 2 \mathrm{~m}$. Generally, the dogs stood quietly in a corner of the caige or else slept during the experiments. The electrical activity of the duodenum was recorded in such manner that complete cycle of the IDME( wals observed. Phase III of the IDMEC wats seen to migrate over the duodenum from one pair of electrodes to another. This phase was preceded by an irregular spiking activity (phase II) and followed by quiescence (phase 1), thus allowing its recognition. Thirty minutes after phase III wals seen in the duodenum, perfusion of the ThiryVella loop wals begun. When the four hour perfusion was completed, the electrical recording wals prolonged until phase III of the II)MEC recurred.

\section{P A R A M E T ERS STU DI E I)}

IDMEC in duodenum

The main goal of this study was to determine whether the IDMEC continues to cycle in the duodenum while perfusing the Thiry-Vella loop with different solutions. Phase III of the IDMEC was accurately identified by analysing its configuration (two to five minute long period of strong spiking activity) and its caludad migration from one electrode to another.

\section{Timing of reappearance of IDMEC}

In many experiments, phase III activity was never seen during the perfusion period. In these experiments we mealsured the time between the end of the perfusion and the moment at which phase III of the IDMEC reoccurred. This measurement included the final washout of the loop.

\section{$V$ olume and glucose concentration of effluent}

The volume of the effluents from the Thiry-Vella loops wals measured and the concentration of glucose determined when the perfusate contained glucose. The results were expressed as the total volume output from the Thiry-Villa loop during the perfusion, and as the total amount of glucose collected during the perfusion of the loop.

S T A T I S T I C S

Three experiments with each of the perfusiates were carried out in each dog. Differences in mean values were compared using the Friedman test."

\section{Results}

The results are summarised in the Table.

CONTROL TRACINGS

Control tracings were obtained three weeks after the operation in the absence of perfusion. These 
Table Results obtained by perfusing jejunal and ileal Thiry-Vella loops

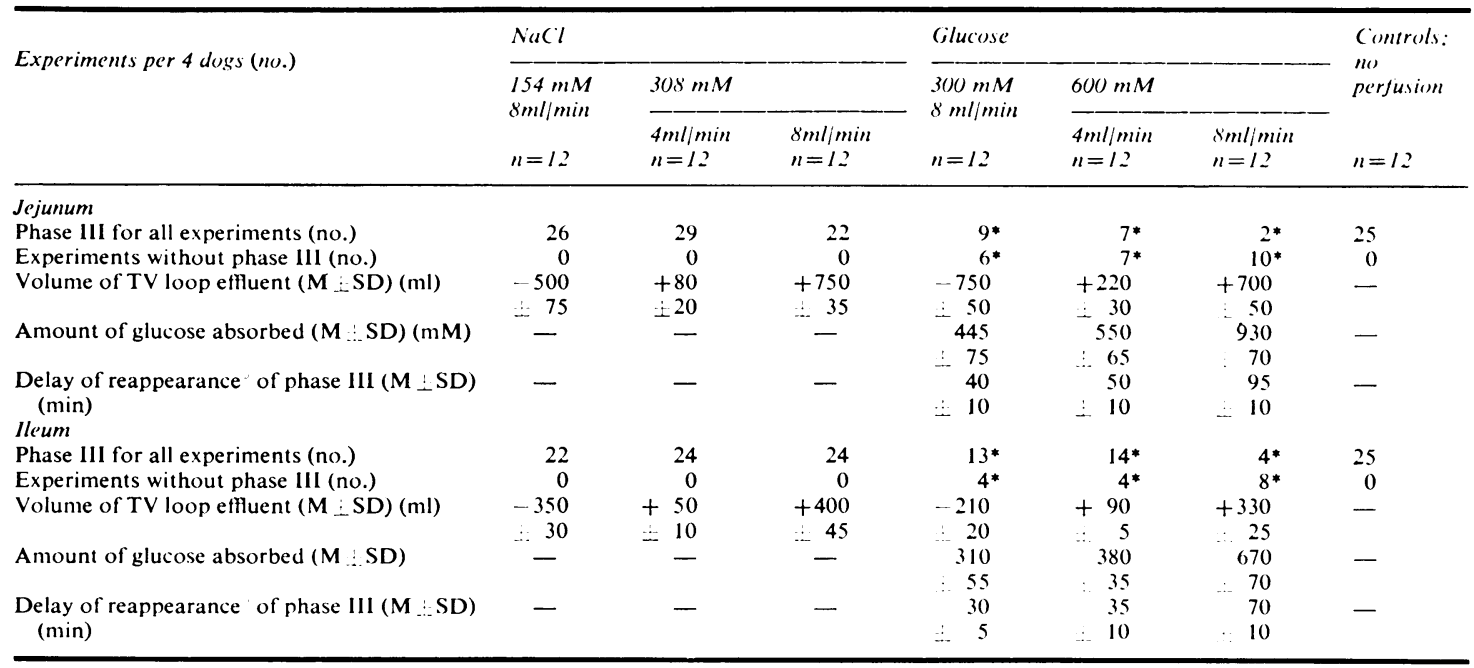

* Concerns only the experiments during which no phase 111 was observed.

Volume of TV loop effluents indicates the difference between the volume introduced into the loop and that collected from the loop. $€$ indicates secretion of water from the loop. $\cup$ : significantly different at $\mathrm{p}<0.05$ from controls and $\mathrm{NaCl}$ experiments.

experiments showed a regular cyclic recurrence of the IDMEC in the duodenum of all dogs. The mean period of the cycles was about 95 minutes. without difference between the four dogs with a jejunal Thiry-Vella loop and the four dogs with the ileal Thiry-Vella loop.

\section{$\mathrm{NaCl}$ PER F USIONS}

Perfusion of the jejunal and ileal Thiry-Vella loops with $154 \mathrm{mM} \mathrm{NaCl}$ or with $308 \mathrm{mM} \mathrm{NaCl}$ did not significantly alter the period of regular occurrence of the IDMEC in the duodenum. Furthermore, no changes were noted when the rate of perfusion of $\mathrm{NaCl} 308 \mathrm{mM}$ was $4 \mathrm{ml} / \mathrm{min}$ or $8 \mathrm{ml} / \mathrm{min}$.

The volumes of the effluents varied with the different perfusates. With $\mathrm{NaCl} 154 \mathrm{mM}$ perfused at $8 \mathrm{ml} / \mathrm{min}$. net absorption of water occurredthat is, the volume perfused was larger than the total volume of effluents. In contrast. perfusion with $\mathrm{NaCl} 308 \mathrm{mM}$ was followed by a net secretion of water that was small when the flow ratte wals $4 \mathrm{ml} / \mathrm{min}$ and larger when it was $8 \mathrm{ml} / \mathrm{min}$.

(i I. U C O S E P E R I: U S IO N S

Perfusion of the Thiry-Vella loops with glucose solutions consistently decreased the number of phase III seen in the duodenum. When compared with the control experiments with both the jejunal and ileal Thirty-Vella loops $(2.5+25=50$ phase III observed during 24 experiments), perfusion with glucose $300 \mathrm{mM}$ at $8 \mathrm{ml} / \mathrm{min}$ was followed by at significant $(p<0 \cdot 05)$ decrease in the number of phase III $(9+13=22$ phase III during 24 experiments). This decrease was significantly greater when glucose $600 \mathrm{mM}$ at $8 \mathrm{ml} / \mathrm{min}$ wals used, only $4+2=6$ phase III being observed during 24 experiments. No significant difference was noticed whether glucose at $300 \mathrm{mM}$ at $8 \mathrm{ml} / \mathrm{min}$ or glucose $600 \mathrm{mM}$ at $4 \mathrm{ml} / \mathrm{min}(7+14=21$ phase III during 24 experiments) were used. However, the total number of phase III occurring during the perfusion of the jejunal loops with all glucose solutions $(9+7+2=18$ phase III observed during 36 experiments) was significantly $(p<0 \cdot 001)$ smaller than the number of phase III observed when ileal loops were perfused $(13+14+4=31$ phase III observed during 36 experiments).

The net amount of glucose absorbed from both the jejunal and ileal Thiry-Vella loops was larger with glucose $600 \mathrm{mM}$ at $8 \mathrm{ml} / \mathrm{min}(932+670=$ $1602 \mathrm{mM}$ ) than with 600$) \mathrm{mM}$ at $4 \mathrm{~m} / \mathrm{min}(548$; $378=926 \mathrm{mM})$. No significant difference wals noticed between glucose $300 \mathrm{mM}$ at $8 \mathrm{ml} / \mathrm{min}$ and glucose $600 \mathrm{mM}$ at $4 \mathrm{ml} / \mathrm{min}$. Finally, the amount of glucose absorbed from the jejunal Thiry-Vella loops $(445+548+932=1925 \mathrm{mM})$ was larger $(\mathrm{P}<0.05)$ than that absorbed from the ileal ThiryVella loops $(310+378+670=1358 \mathrm{mM})$.

C O MPI. E T E IN N I B I I IONO O I

1) U () I) E N A L, I I) M E C

No phase III of the II)MEC was observed in $6+4$ $=10$ out of 24 experiments when both the jejunal 
and ileal Thiry-Vella loops were perfused with glucose $300 \mathrm{mM}$ at $8 \mathrm{ml} / \mathrm{min}$, and in $7+4=11$ out of 24 experiments when glucose $600 \mathrm{mM}$ at $4 \mathrm{ml} /$ min wals perfused. Phase III were not seen in $10+8=18$ out of 24 experiments when glucose $600 \mathrm{mM}$ at $8 \mathrm{ml} / \mathrm{min}$ was used.

Perfusion of the jejunal Thiry-Vella loops with all glucose solutions was associated with the absence of phase III in $6+7+10=23$ out of 36 experiments, while $4+4+8=16$ out of 36 experiments when the ileal Thiry-Vella loops were perfused.

During the period of IDMEC inhibition, the pattern of myoelectrical activity in the duodenum was made of spike potentials superimposing 20 to $25 \%$ of the slow waves, indicating a post-feeding pattern.

In these cases the IDMEC did not reoccur immediately after the end of the perfusion period. despite the fact that washout of the perfusate cleared the loops within five minutes of any remaining glucose in the lumen. When glucose 300$)$ $\mathrm{mM}$ at $8 \mathrm{ml} / \mathrm{min}$ or glucose $600 \mathrm{mM}$ at $4 \mathrm{ml} / \mathrm{min}$ were perfused, the first phase III was observed to reoccur after 30 to 45 minutes. while the delay reached 60 to 90 minutes when glucose $600 \mathrm{mM}$ at $8 \mathrm{ml} / \mathrm{min}$ was perfused.

\section{Discussion}

The results obtained in our study show that the IDMEC is inhibited by feeding through extraintestinal mechanisms, at least partly. Indeed. no intraluminal continuity was left between the ThiryVella loop and the duodenum so that the inhibitory effects must have been driven through central -neural or humoral-pathways. The precise nature of these mechanisms is not known. However, our study shows that these mechanisms are not specific to any one part of the small bowel, because the IDMEC was disrupted in the duodenum by perfusing nutrients in either a jejunal or an ileal Thiry-Vella loop.

These extraintestinal non-specific mechanisms do not seem to be significantly influenced by the flow rate or osmolality of the solutions introduced in the Thiry-Vella loops. In the $\mathrm{NaCl}$ experiments, IDMEC was not altered by changes in net absorption or net secretion of water. No significant difference was observed whether the flow rate of the solutions was 4 or $8 \mathrm{ml} / \mathrm{min}$. In the glucose experiments, the same effects were observed with either glucose $300 \mathrm{mM}$ at $8 \mathrm{ml} / \mathrm{min}$ or glucose $600 \mathrm{mM}$ at $4 \mathrm{ml} / \mathrm{min}$, while these experiments differed by the flow rate as well as by the fact that a secretion of water occurred with glucose $600 \mathrm{mM}$ at $4 \mathrm{ml} /$ min and an absorption of water occurred with glucose 300$) \mathrm{mM}$ at $8 \mathrm{ml} / \mathrm{min}$.

On the contrary. the inhibitory factors released from the Thiry-Vella loop seemed to depend. at least partly, on glucose absorption in the ThiryVella loop. Previous investigators have shown that the interruption of the IDMEC after feeding dogs orally could be related to both the biochemical nature of the food components and the caloric load of the meal.":" Moreover, other workers have reported that changes in intestinal absorption of a given meal-for instance, by introducing fat directly into the jejunum in the absence of bile salts-could result in subsequent changes in the duration of interruption of the II)MEC ( . ' These observations suggest that IDME( inhibition is related with intralumnial absorption of nutrients. However, in our study, we observed that. when the IDMEC was abolished completely during four hours of glucose perfusion, a considerable time elapsed before II)ME( reappeared. Therefore, the IDME( was inhibited even though no glucose remained in the lumen of the Thiry-Vella loop. These findings suggest that the duration of IDMEC inhibition was longer than the duration of mucosal contact with the glucose containing perfusate.

Finally, the observations reported in the present study can be put together with previous findings having shown that the IDME( could be interrupted in a Thiry-Vella loop while feeding a dog orally." This suggests that II)ME( interruption results from a two-waly system, with a sensitive end in the mucosa of the bowel and an effectory end in the intestinal smooth muscle. Between these two ends, inhibitory informations and orders are transmitted through mechanisms which caln be of neural or humoral nature. Nervous mechanisms may play a role through nerve endings situated in the bowel wall which are known to be sensitive to many biochemical stimuli." " " However, section of neural pathways such als the valgus ${ }^{1:}$ or the splanchnic nerves" did not demonstrate considerable change in the inhibition of the IDMEC after feeding. Hormonal mechanisms are now thought to play a major role, since infusion of several hormones-insulin, ${ }^{17} \mathrm{CCK},{ }^{16}$ gastrin ${ }^{17}$-has been shown to inhibit the myoelectric complex. However, the responsibility of any one of these hormones remains to be clearly identified.

We would like to thank Dr M Sarr (Mayo (linic. Rochester. Minnesota. USA) for his aid and his helpful suggestions in writing this article. 


\section{References}

'Szursewski JH. Migrating electric complex of the canine small intestine. Am J Physiol 1969; 217:1757 6.3 .

¿De Wever J, Eeckhout C. Vantrappen G. Hellemans J. Disruptive effects of test meals on interdigestive motor complex in dogs. Am J Physiol 1978; 235: [:661 $1: 5$

:Schang JC. Sava P. Angel F. Lambert A. Grenier JF. Specific effects of different food components on intestinal motility. Eur Surg Res 1978; 10:425 32.

'Dewever I, Eeckhout (', Vantrappen G, Hellemans J. How does oil disrupt the interdigestive myolectric complex? In: Christensen J, ed. (iastrointestinal motility. New York: Raven Press, 198(); 295 -8.

Weisbrodt NW, Copeland EM. Thor PJ, Dudrick SJ. Small bowel motility during intravenous hyperalimentation in the dog. (iaveroenterology 1975; 68: A154/1011.

"Crenner F. Lambert A, Schang JC. Angel F. (irenier JF. Analog automated analvis of small intestinal electromyogram. Med Biol Eng Comp 1980 ; (In press.)

iFordtran JS, Ingelfinger FJ. Absorption of water. electrolytes, and sugars from the human gut. In: Code CF, ed. Handbook of physiology. section 6, volume 3. Baltimore: Williams and Wilkins, 1968; 14579() .

-Bueno L. Fioramonti J, Ruckebusch M. Rate of flow of digesta and electrical activity of the small intestine in dogs and sheep. J Physiol (Lond) 1975; 249:69 85 .

"Lehmann E:I. Non-parametric statistical methods based on ranks. San Francisco: McGraw-Hill, 1975.

"Schang JC'. Sava P. Dauchel J, Angel F, (irenier JF. Relation entre motricité et absorption intestinales. Pathol Biol (Paris) 1977; 27:389 93.

"Hunt JN. The site of receptors slowing gastric emptving in response to stouch in test meals. $J$ Pliviol (Lond) 196(); 154:270) 6.

1:Sharma KN. Nasset ES. Electric activity in mesenteric nerves after perfusion of gut lumen. $A m \mathrm{~J}$ Phyviol 1962; 202:7253().

1:Marik F. Code ( F. Control of the interdigestive myelectric activity in dogs by the vagus nerves and pentagastrin. (;astroenterology 1975; 69:387 95.

"Marlett JA. Code C F. Effect of celiac and superior mesenteric ganglionnectoms on interdigestive mroelectric complex in dogs. Am J Phiviol 1979; 237: E432-E436.

1:Bueno L. Ruckebusch M. Insulin and jejunal electrical activity in dogs and sheep. Am J Phyiol 1976; 230: 153844.

"iMukhopadhyay AK. Thor PJ. Copeland FM. Johnson L.R. Weisbrodt NW. Effect of cholecrstokinin on myoelectric activity of small bowel of the dog. Am J Physiol 1977; 232:E44-E47.

1:Thomas PA. Schang JC. Kelly KA, (jo) VLW. (an endogenous gastrin inhibit canine interdigestive gastric motility? (jastrocenterology 198(); 78:716 21: 